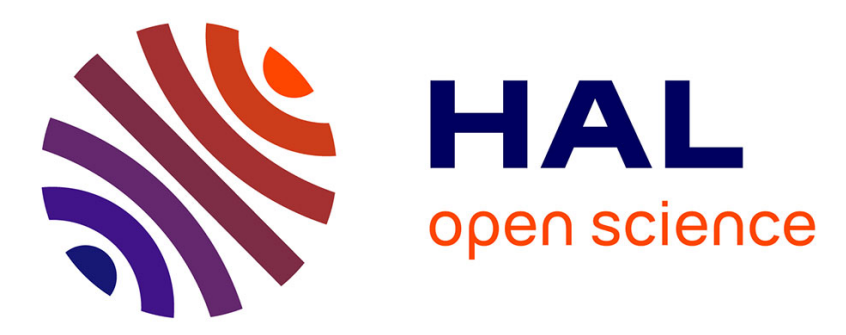

\title{
Some issues about the introduction of first concepts in linear algebra during tutorial sessions at the beginning of university
}

\author{
Nicolas Grenier-Boley
}

\section{- To cite this version:}

Nicolas Grenier-Boley. Some issues about the introduction of first concepts in linear algebra during tutorial sessions at the beginning of university. Educational Studies in Mathematics, 2014, 87 (3), pp.439-461. 10.1007/s10649-014-9564-0 . hal-01720647

\section{HAL Id: hal-01720647 \\ https://hal.science/hal-01720647}

Submitted on 1 Mar 2018

HAL is a multi-disciplinary open access archive for the deposit and dissemination of scientific research documents, whether they are published or not. The documents may come from teaching and research institutions in France or abroad, or from public or private research centers.
L'archive ouverte pluridisciplinaire HAL, est destinée au dépôt et à la diffusion de documents scientifiques de niveau recherche, publiés ou non, émanant des établissements d'enseignement et de recherche français ou étrangers, des laboratoires publics ou privés. 


\title{
SOME ISSUES ABOUT THE INTRODUCTION OF FIRST CONCEPTS IN LINEAR ALGEBRA DURING TUTORIAL SESSIONS AT THE BEGINNING OF UNIVERSITY
}

\author{
NICOLAS GRENIER-BOLEY
}

\begin{abstract}
Certain mathematical concepts were not introduced to solve a specific open problem but rather to solve different problems with the same tools in an economic formal way or to unify several approaches: such concepts, as some of those of linear algebra, are presumably difficult to introduce to students as they are potentially interwoven with many types of difficulties as formal ones and far away from the actual knowledge of the students. The purpose of this paper is to propose a methodology for studying the introduction of such concepts in linear algebra during tutorial sessions at the beginning of university, the wording of the concepts being yet presented during lectures. For this purpose, we amend a general methodology of Pariès, Robert and Rogalski inside the general framework of Activity Theory. This methodology lets us take into account several specificities of these concepts and studies the mathematical activity the teacher organises for students and the way he manages the relationship between students' actual activities and mathematical tasks. We also present an implementation of this methodology based on a French university course to illustrate our approach and discuss its possibilities.

linear algebra and FUG concept and methodology and students' activity and teacher's activity
\end{abstract}

\section{INTRODUCTION}

At the beginning of their university studies, students meet several new mathematical concepts for which the distance between what they know and what they have to do with them is great. Among these, FUG concepts are considered to be the most arduous ones, insofar as they concentrate difficulties of different nature: a FUG concept is a mathematical concept that introduces generality by unifying earlier objects through a new formalism (Robert, 1998); basic examples of such concepts include vector spaces (Dorier, 2000) and the $(\varepsilon, N)$-formalization of the convergence of a real sequence (Robert, 1998). To illustrate the type of difficulties that can occur during the introduction of a FUG concept, let us consider the following exercise; it has been proposed to first year university students during the first tutorial session corresponding to a linear algebra course, having just seen the definition of the notion of vector space:

"In $\mathbb{R}^{2}$, define the operations $(x, y)+\left(x^{\prime}, y^{\prime}\right)=\left(x+x^{\prime}, y+y^{\prime}\right)$ and $\alpha .(x, y)=$ $(\alpha x, 0)$. Is $\mathbb{R}^{2}$ endowed with these operations a vector space?".

Although it is a classical exercise, there is a real gap between the mathematical acti-vities employed at the end of secondary school and the ones potentially involved in this exercise. First of all, the question is open and 
the statement of the exercise does not suggest any method. The students thus have to consider the axiomatic nature of the definition of vector space, consequently split their reasoning into several steps in accordance with this definition and decide whether or not each axiom is satisfied: in fact, it is necessary and sufficient to show that the axiom "for any $v$ in $\mathbb{R}^{2}, 1 . v=v$ " does not hold. Proving that each axiom does or does not hold for the respective operations necessitates a combination of complex tasks such as conversion between (representation) registers (Duval, 2006), appropriate use of logic and formalism, and the production of a proof or a counterexample, all of which require expertise and flexibility.

We share the hypothesis according to which there is no problem to give full meaning to a FUG concept (Dorier, 2000). In such a case, students' learning cannot result from the mathematical tasks proposed to them independently from the teacher's interventions, hence the way he organises his teaching interventions during the corresponding tutorial sessions is crucial in many ways:

-How does the teacher manage the introduction of a FUG concept? How does he take into account students' heterogeneity?

-What kind of assistance does he offer to students? Which mathematical activities are their responsibility?

-Does he refer to the lectures? If so, how and when?

The main purpose of this paper is to propose a methodology in order to study the introduction of FUG concepts during the tutorial sessions corresponding to an introductory linear algebra course: more precisely, our goal is to define systematic indicators (as objective as possible) to characterize the teacher's choices during tutorial sessions related to such concepts. Admittedly, the beginning of the teaching of linear algebra is often considered to be a particular case of what is proposed at the beginning of university: from our viewpoint, the choice of this very teaching moment might be characteristic among the teaching phases in which there is no proximity between students' knowledge and the course. In this sense, one may hope that such a methodology could be generalised to a certain extent to other teaching moments dedicated to the introduction of FUG concepts.

The paper is organised as follows. In Section 2, we present the theoretical framework and the associated hypotheses that will be used, recall some specificities of the linear algebra field at the beginning of university and give the precise definition of a FUG concept; the interests of our framework to validly study the introduction of a FUG concept in linear algebra inside the classroom are also highlighted. In Section 3 we design the methodology of our research, its implementation being illustrated on a particular video corpus based on a French university course in Section 4. We also describe some results associated to this corpus that are then discussed in Section 5.

\section{TheOreticAl BACKGROUND}

2.1. Some facts about secondary education and university in France. In France, secondary education is divided into seven grades inside two schools: the collège for the first four years following primary school and the lycée for the next three years. The baccalauréat is the end-of-lycée diploma students 
sit in order to enter university. University is divided into three grades: $\mathrm{Li}$ cence (Bachelor), Master (Master) and Doctorat (Doctorate). In addition Licence and Master are organised in semesters (6 for the Licence and 4 for the Master) which are divided into several courses, each devoted to a specific field.

For our purpose, the main difference between secondary school and university concerning the teaching of Mathematics is the way it is organised. For a given grade in secondary school, each course is usually taught by a single teacher who is free to organise the courses and the exercises according to the current programmes, and thus has opportunities to create links between the course and the exercises. This is not the case at university where lectures and tutorial sessions are temporally separated and often supervised by two different teachers: for a given university course, students attend the lectures and then split into smaller groups for the corresponding tutorial sessions. Lectures are delivered by the teacher responsible for the course with minimal interaction. During tutorial sessions, students have to apply the knowledge introduced in the lectures to particular situations (be it exercises, problems...) in the presence of a teacher (the tutor) who organises interactions, possible helps and corrections. For most students, the knowledge of the course is practised and acquired during these sessions: in this regard, their study is a natural focus of interest, as well as their possible links with the lectures as already pointed out.

2.2. General framework. We base our approach on Activity Theory (Leontiev, 1975; Leplat, 1997) and its adaptation to the teaching of mathematics (Rogalski, 2013; Robert and Hache, 2013). The main purpose of this framework is to better understand the teaching and learning of mathematics by analysing students and teachers' activities as individual subjects. Within this framework, the main concept is the concept of activity which implicitly refers for us to a goal-oriented activity, that is "the activity of an individual subject, with individual motivations, within a specific situation"(Rogalski, 2013): other senses of this concept are used in the literature - for example, the activity of a collective system (Engeström, 1999) - but are not taken into account in our study. An essential element is the distinction between task and activity: whereas the task is understood as "the goal to be attained under certain circumstances", the activity is "what the subject engages during the completion of a task", including internal and external actions; in other words, "the activity relates to the subject, while the task relates to the objects of the action" (Rogalski, 2013).

Our framework incorporates general hypotheses about student learning by connecting Activity Theory to some other constructivist theories about mathematical learning. In particular, from a Piagetian point of view, it is considered that an individual subject constructs knowledge about a specific object through actions on this object. From a Vygotskian point of view, it is considered that a student "is an individual and social subject, who will construct tools for thought within social interactions". In the literature, these viewpoints either appear to be in opposition or to be complementary, depending on the theoretical backgrounds of the considered studies. Following 
Rogalski (2013), we will consider that they can be articulated by supposing that student' learning with respect to a given mathematical content at a given teaching moment can either be an internal individual process (the student works on his own) or part of a social process (the student has the possibility to take part in a collective work, possibly after didactic interventions of the teacher); in general, these two types of processes are not associated with similar contents.

To sum up, it is considered that student learning results from his activities in response to (mathematical) tasks. Moreover, "students' activities are provoked by the teacher, and depend on some of the teacher's choices, on their work itself and on the way the teacher intervenes on their work" (Robert, 2012). We also hypothesize that the identification of students' proximal development zone (PDZ) by the teacher is fundamental: it is "situated between the current level of development, defined by what the [student] is capable of doing or solving autonomously, and what the [student] can do or solve with the help of others" (Rogalski, 2013); this concept is particularly relevant in the case of a new knowledge.

2.3. Analyses of mathematical tasks and students' activities. The general framework of Activity Theory allows us to analyse students and teachers' activities inside the classroom. Following Robert and Hache (2013), we now explain in which way this general framework can be adapted to take into account the specificity of mathematics teaching: in particular, we present further theoretical hypotheses and methodological tools.

Suppose that a mathematical statement is given to students during a certain teaching intervention inside the classroom: by hypothesis, studying students' activities during this intervention suppose to study their actions including what they do, say, think, do not do, do not say, etc. - during the completion of each mathematical task that is attached to the statement with anything added by the teacher. We distinguish two stages in the process of analysis of such a situation: an a priori analysis of the mathematical tasks involved in the statement and an a posteriori analysis of the class period corresponding to the teaching intervention. Each analysis is based upon additional general hypotheses on students' learning.

2.3.1. A priori analyses of mathematical tasks. An a priori analysis of the tasks that are potentially involved in a mathematical statement consists of determining what activities students will be able to take part in for this statement, with their supposed knowledge: by hypothesis, these tasks are supposed to have an influence on students' activities, and therefore on students' learning. Moreover, it is hypothesized that "the possible ways to mobilize, combine, and recognize the knowledge to be used in exercises are the main factor in constructing student knowledge" (Robert and Hache, 2013). During this analysis, we are thus interested in determining the various and specific knowledge adaptations potentially involved in the statement, taking into account students' level of schooling and acquired knowledge. We note that there exist other mathematical tasks analyses that are less specific in terms of mathematical knowledge to apply, but rather insist on the nature of 
students' work (making and testing conjectures, looking for patterns, memorization, use of formulas or algorithms...) (Stein, Grover and Henningsen, 1996).

When a mathematical task is a direct application of an explicit knowledge, we refer to it as a simple and isolated task (SIT). When a task is not a simple and isolated task, we determine the combinations of knowledge adaptations that students must do, using the following list of knowledge adaptations classified into (non independent) categories (Horoks and Robert, 2007; Robert and Hache, 2013):

(A1) Acknowledgement of the terms that allow the theorem, formula, definition, method to be used.

(A2) Introduction of intermediate terms, letters, notations,...

(A3) Change of frames (Douady, 1986), representation registers (Duval, 2006), points of view (Vandebrouck, 2013).

(A4) Introduction of steps in the solution (usual or not).

(A5) Use of previous questions in solving a problem.

(A6) Existence of different choices in the solution, forced or not.

(A7) Lack of new knowledge.

The result of this analysis is the determination of students' expected activities in relation with the considered statement, that is the activities that we can predict consi-dering their supposed knowledge. By hypothesis, the expected activities are characterised by the different knowledge adaptations that students must do: explicitly, it is supposed that the more students work on diversified tasks in terms of knowledge adaptations, the more the activities are varied and favourable for learning.

2.3.2. A posteriori analyses. The a priori analysis of a statement is completed by an a posteriori analysis of the corresponding teaching intervention: for this, we incorporate any element that is added by the teacher, be it collective didactic interventions that could or could not be within students' PDZ (such as questions, recalls, hints, helps (direct, indirect), explanations, partial corrections and any type of assistance) or anything that is related to the organisation of students' work. The hypothesis here is that student knowledge "depends not only on proposed tasks and the actions they may provoke, but also on the way in which these tasks are worked on by students" (Robert and Hache, 2013).

The purpose of this analysis is to reconstitute students' activities from the analysis of the class period (that shall be detailed in the next section). For this, we make a further theoretical hypothesis: as students' activities are partly internal hence inaccessible, we will only have access to students' possible activities which are presumably closed to their real activities and for which we hypothesize that they give a pertinent access to students' learning. By definition, students' possible activities are those that have been (at least) partly done by a majority of students, considering the analysis of the teaching intervention.

2.4. FUG concepts. Some mathematical concepts were not invented to solve a specific problem but rather to solve different problems with the same tools - such as those arising in the modern theories of vector spaces, 
of groups, of topological spaces - or to unify several definitions (for example, the definition of a category which is an axiomatic capture of what is commonly found in many algebraic structures such as sets, rings, fields, algebras, modules (Mac Lane, 1998)). When a new mathematical concept (object, method or tool) is taught to students, a way to measure the distance between this concept and previous elements of knowledge is to try to detect three functions attached to it: the formalizing characteristic, the unifying characteristic and the generalizing characteristic (Robert, 1987; Dorier, 1995; Robert, 1998; Vandebrouck, 2013).

The formalizing characteristic of a concept consists in a new formalism - including new vocabulary, new symbols and unification of previous coexisting formalisms - which has not been fully introduced yet. For example, at the beginning of university, the formalism of the $(\varepsilon, N)$-definition of the convergence of a real sequence is new, especially in the formal translation of the definition, although the symbols involved in it are already known.

The unifying characteristic of a concept means that the concept unifies previously known concepts of which it has been abstracted. For example, the notion of vector space introduced at the beginning of university has a unifying characteristic as it can be used to work with real polynomials, real sequences or the set of solutions of a homogeneous linear differential equation in a similar way.

The generalizing characteristic of a concept refers to the fact that the concept generalizes or extends one or several pre-existing elements of knowledge. For example, the notion of topological space which is usually introduced during the Master has a generalizing characteristic because it extends the notion of metric space introduced during the Licence.

When a concept has all three characteristics at the same time, it is called a FUG concept: it means that this concept introduces greater generality by unifying earlier objects through a new formalism than other notions, extension of old ones or directly tied to a given question (Robert, 1998; Vandebrouck, 2013). As already said, two families of FUG concepts have been particularly studied: those of linear algebra, for example vector spaces, vector subspaces (spanned by a family of vectors) (Dorier, 2000), those of real analysis, for example the $(\varepsilon, N)$-definition of the convergence of a real sequence or the $(\varepsilon, \eta)$-definition of the limit of a real function at a point (Robert, 1998). Recently, it has been shown that the interpretation of several elements of knowledge as FUG concepts at the beginning of a topology course during the third year of Licence could lead to a better understanding of students' difficulties in relation to these concepts (Bridoux, 2011).

2.5. Linear algebra. From an epistemological point of view - a comprehensive epistemological analysis of the genesis of linear algebra can be found in Dorier (1998) or Dorier (2000), part 1, from which our few observations are borrowed - the first unification of several key notions of linear algebra (such as the notions of basis and dimension) from a global geometric perspective dates from Grassmann's misunderstood work $(1844,1862)$. The general axiomatic definition of a vector space was first given by Peano in 1888 after his reading of Grassmann's work; the axiomatic presentation of the theory became predominant in the 1930's then in the 1940's in France 
after the publication of fundamental books, among which those by van der Waerden, Banach and Bourbaki.

In France, it is a tradition to present the formal axiomatic theory of vector spaces to first-year university students by trying to keep a link with their acquired knowledge from secondary school: yet, it appears that students have difficulties with prerequisites in logic, set theory and geometry, in using the first notions of linear algebra, in seeing the link with familiar situations and in flexibly converting between registers (Dorier, 2000). Moreover, epistemological causes for students' difficulties in linear algebra can also be highlighted. Indeed, the formalism of the underlying concepts is a great obstacle for students: it appears that this formalism is intrinsically difficult, as this difficulty is inherent in the unification and generalization; more, the simplification offered by mastering these concepts is postponed as it is correlated to a good understanding of the theory (Dorier, 2000).

2.6. Teaching FUG concepts: the case of linear algebra. To introduce a new concept to be taught to students, it is always interesting to find a fundamental situation, that is a problem where this new concept is the adequate and unique tool to be used to solve the problem (Brousseau, 1997): after such a situation, the teacher can institutionalise this concept in the sense that he consecrates it as a formal piece of knowledge that can be used as a tool afterwards (Brousseau, 1997)). For FUG concepts at the beginning of a linear algebra course, it seems that the existence of such a situation is unlikely as it would require a great effort of formalization and abstraction and to take into account different types of difficulties and epistemological specificities (see previous Subsections). We thus share the hypothesis that it is not possible to introduce them meaningfully by means of a fundamental situation (Dorier, 2000; Vandebrouck, 2013).

This strong hypothesis raises the question of the possibilities offered to a teacher who wants to introduce such concepts. As this introduction can only be partial, an optimal strategy would be to institutionalise part of the concept first and then to give students a problem to give it meaning (Dorier, 2000). For many reasons, this strategy is not always possible and the teacher can also choose to institutionalise the whole concept first and then concentrate on problems and exercises in order to "bring students closer" to this concept.

In any case, the role of the teacher during teaching interventions dedicated to the introduction of FUG concepts in linear algebra is essential given that students' learning cannot only result from their activities in response to mathematical tasks. From our point of view, the choice of our theoretical framework is particularly adapted to conduct a valid study of such teaching interventions. First, several methodological tools that allow us to analyse students 'activities are still pertinent for FUG concepts (see Subsection 2.2). Next, the specificities of linear algebra's FUG concepts lead us to choose analyses that take into account teachers' activities: the way he organises the corresponding teaching interventions, the type of assistance he offers within or above students' PDZ. We shall now precisely describe the methodology designed for our purpose. 


\section{Methodology}

The methodology used to design this research is based upon a general methodology due to Pariès, Robert and Rogalski (2009) (see also Robert and Hache, 2013) whose purpose is to study the teaching of a given mathematical topic inside the framework described in the previous Section. It consists of several degrees of analysis of a classroom session, which are called acts, ranging from the more general to the finest depending on the type of research. Our methodology will be composed of four acts: the first three acts are taken out from the general methodology while the fourth one is new and adapted in accordance with our purpose. It has been designed to analyse the teaching intervention devoted to a given statement: this session should be video-recorded and transcribed and several preliminary informations are required (for example, informations about the syllabus, the specificity of the underlying concept(s), the teaching project of the teacher and his representations of the class).

3.1. First act. The first act, which has already been precisely described in 2.3.1, consists of an a priori analysis of the mathematical tasks potentially involved in the studied statement: by hypothesis, these tasks are supposed to have an influence on students' activities, and therefore on students' learning. As a result, we determine students' expected activities, that is the activities that are characterised by the different knowledge adaptations that we can predict considering their supposed knowledge.

3.2. Second and third act. The second and third act complete the $a$ priori analysis of the first act by a posteriori analyses of the teaching intervention corresponding to the studied statement (see 2.3.2).

The second act is an analysis of the real teaching intervention based on a video-recording. Its purpose is to produce a chronological table that compares mathematical tasks as expected by the a priori analysis with the teacher's collective interventions (that are supposed to have a crucial influence on students' activities). We first produce a chronological list of mathematical tasks as they are encountered throughout the teaching intervention, each mathematical task determining a phase: for this, we are helped by the mathematical tasks that have been determined during our a priori analysis. For each phase, we note the nature of students' work, including the length of the phase, the format (individual, collective, etc.), the output of the task (individual research, correction, etc.) and refer to the mathematical task of the a priori analysis. For each phase, we also compare the nature of students' work to the teacher's collective didactic interventions (in the sense that has been specified in 2.3.2) and to the type of tasks proposed to them (researching, writing, recopying, listening, etc.). In order to give a comprehensive and readable report of this analysis, we organise it chronologically in a three column table: the left column contains he nature of the work organised by the teacher, the center column contains the collective interventions of the teacher and the right column contains the type of tasks.

The third act consists in the determination of students' possible activities (see 2.3.2) using the table produced in the second act. More precisely, this chronological table contains traces of activities be they encouraged by the 
teacher or not: possible activities are those that we can estimate were done by a majority of students during the teaching intervention. Afterwards, students' possible activities are compared to students' expected activities determined during the first act: this is a way to compare what has been predicted by the a priori analysis with what has been effective (and perhaps facilitated by the interventions of the teacher) during the teaching intervention.

3.3. Fourth act. The purpose of this new act is to define an indicator to measure (or even characterize) the global organisation of the teaching intervention by the teacher based on the table constructed in the second act. This act has been constructed in order to try to characterize some of the teacher's choices during tutorial sessions related to FUG concepts in a linear algebra course.

The first step is to label the different phases determined during the second act, considering notably the relative presence or absence of interactions between the teacher and students. For this, we use four types of label (which will be defined and explained below): prologue, individual research, correction or postlogue. To each statement, we then associate the (ordered) 4 -tuple $(x, y, z, t)$ where $x$ (respectively $y, z, t)$ represents the integer part of the time proportion devoted to the prologue (respectively the individual research, the correction, the postlogue) during the teaching intervention. For us, this 4-tuple will be a global management indicator of the considered statement. The second step is to try to group the statements for which the global management indicator is similar in a single statement type, and try to interpret these types with respect to the mathematical tasks involved.

Needless to say, the global management indicator is defined through a radical loss of information in comparison with the second act of this methodology: indeed, we might have to group together some consecutive phases in order to label them and the chronology is not fully taken into account. Moreover, the second step is based on a double conscious bet: to be able to classify in a single type the statements that have a similar global management indicator and to be able to give an interpretation of these types according to the mathematical tasks that are involved. For this, we will use the informations obtained in the first three acts.

For us, this loss of information is deliberate and based on the very specificity of the teaching moment that has been chosen. As the teaching of FUG concepts at the beginning of a linear algebra course is problematic for different reasons (see Subsections 2.4 and 2.5), the teacher do not have many possibilities (see Subsection 2.6): we thus hypothesize that the global management indicator attached to a statement, however simplistic it appears, gives a simple and still pertinent access to the way the teacher globally organises his teaching intervention. More, the global management indicator of a given statement is a report of the time spent on each type of phase during the teaching intervention: it is supposed to be an index of the importance given by the teacher to this type of phase in relation with the statement.

We now define and explain the four types of labels used in the global management indicator in relation with our main purpose. 
The prologue is the phase which occurs before any individual research (or possibly after a brief phase of individual research) during which the teacher recalls facts (definitions, results, methods, etc.) and/or asks questions to the students. It can also be an opportunity for him to give direct or indirect help, to suggest a resolution strategy, or to take charge a priori of some elements of the correction. As already mentioned, the question of the link between lectures and tutorial sessions is crucial: for us, the prologue phase is also a way of taking this dimension into account.

The individual research is the phase in which the teacher allows the students to search for a solution to the whole exercise (or part of it) on their own. Considering our theoretical hypotheses, this phase is a way to measure the proportion of the exercise in which the students can potentially acquire knowledge during tutorial sessions, and to see which mathematical tasks are their responsibility.

The correction is the phase in the course of which the teacher gives a correction of the whole exercise (or part of it) or asks a student to do it on the blackboard. It can occur after a phase of individual research, in which case the teacher has the opportunity to take into account students' activities that he has possibly detected.

The postlogue is a phase in which the teacher contextualizes the correction of the exercise: providing complementary remarks, comparing different methods or giving examples that illustrate what has just been seen. For us, this phase is a way to see how the teacher manages students' heterogeneity after the correction and how he possibly remains within their PDZ. We also consider the postlogue phase as a mean for the teacher to take charge of several students' difficulties a posteriori.

\section{ImPlementation OF THE METHOdOLOGY: AN EXAMPLE}

4.1. Presentation of the data. The data that we are going to analyse are part of a half-year course given in a French university consisting of three lectures and ten tutorial sessions at the very beginning of a linear algebra course given to first-year students during the second semester. The supervisor of the tutorial sessions (whom we will call Gilles) is different from the supervisor of the lectures, the question of references to the course by Gilles thus being relevant. The sessions have been video-recorded and subtitled. The corresponding syllabus goes from the notion of vector space to the notion of basis: for the sake of completeness, the reader will find a chronological list of the statements given in these sessions in Appendix A. During the first semester, the students have studied the solving of systems of linear equations and matrix operations with the same teacher.

4.2. Two examples of analysis. We give an illustration of our methodology by analysing two statements among those treated during the tutorial sessions by Gilles: we refer to Appendix A for their wording.

4.2.1. Exercise 1, sheet 2. The a priori analysis of mathematical tasks for this exercise having already been done in the introduction, we now focus on the adaptations of knowledge (see Subsection 2.3.1). During the previous lecture, the notions of vector space over $K(K=\mathbb{R}$ or $\mathbb{C})$ and of vector 
subspace have been defined and studied: the supervisor has particularly emphasized the classical vector space structure of $\mathbb{R}^{n}$ over $\mathbb{R}$ for a positive integer $n$.

As already said in the introduction, it suffices to show that the axiom " $\forall x \in \mathbb{R}^{2}, 1 . x=x$ " does not hold: this requires an adaptation of type (A3) for some students because they have to pass from the formal vectorial register $" \forall x \in \mathbb{R}^{2}, 1 . x=x$ " to the vectorial coordinates register " $\forall(x, y) \in \mathbb{R}^{2}$, 1. $(x, y)=(x, y) "$. In this case, they have to produce a counterexample (e.g. $1 .(1,1) \neq(1,1))$, which requires adaptations of type (A1) and (A4) at this stage of the year (respectively for the appropriate use of logic and quantifiers and for the introduction of steps in the reasoning). Note that the operations + and . satisfy the other axioms, so there is only one choice.

Note that this exercise represents students' first encounter with the notion of vector space during tutorial sessions: we can expect them to verify whether each axiom is satisfied or not, all the more so the only axiom that does not hold is the last one in the definition given in the lecture. In this case, they have to split their reasoning into two steps (A4):

- show that $(E,+)$ is an abelian group, either by remarking that the operation + defined in the exercise is the operation that confers to $\mathbb{R}^{2}$ its usual structure of abelian group (A1) or by verifying the four axioms $(\mathrm{A} 1) \times 4$, the formalism of their definitions potentially necessitating a change of register (A3).

- show that three of the axioms for the operation . are satisfied $(\mathrm{A} 1) \times 3$ and that the last axiom does not hold (see above).

We consider that the verification of each axiom requires an adaptation of type (A1) at this stage of the year and is not a simple and isolated task (SIT). We can expect difficulties due to the fact that the notion of vector space is a FUG concept (particularly with the formalism): in this regard, the teacher will probably take charge of some tasks.

The report of the second act of analysis can be found in Figure 1. For this exercise, we describe precisely the third act of analysis. The teacher gives direct help from the start and decomposes the task into subtasks. He takes charge of some of them: identification of the classical addition of $\mathbb{R}^{2}$, proof of an axiom of the external binary operation after a little time for individual research. The students copy down the de-finitions of a closed/external binary operation and the classical vector space structure of $\mathbb{R}^{2}$ and they are led to see that the closed binary operation of the exercise is the classical one. However, the structure of abelian group has not been recalled precisely: yet, two axioms are mentioned by the teacher (existence of a zero element and of an inverse for each element). The only task to which the students have access is the verification of the axioms of the external binary operation. After a short period of individual research, the teacher shows that the external operation satisfies one of these axioms. After another period of individual research, the teacher proves that the last axiom does not hold. At the very end, the teacher mentions that the other axioms are satisfied, without providing any proof. By his collective interventions, the teacher has reduced the original mathematical tasks and we see that students' possible activities 


\begin{tabular}{|c|c|c|}
\hline Nature of the work & Collective interventions of the teacher & Types of tasks \\
\hline $\begin{array}{l}\text { Prologue (5'20") } \\
\text {-Introduction and recalls (4'25") } \\
\left.\text {-Writing of the wording ( } 55^{\prime \prime}\right)\end{array}$ & $\begin{array}{l}\text { The teacher introduces the notion of vector } \\
\text { space to the students and emphasizes its } \\
\text { unifying and generalizing characteristics. } \\
\text { He recalls what a closed/external binary } \\
\text { operation is and writes the wording. }\end{array}$ & Listening. \\
\hline $\begin{array}{l}\text { Collective recap on the notion } \\
\left.\text { of a vector space ( } 4 \text { ' } 26^{\prime \prime}\right) \\
\text {-Enumeration of the axioms of } \\
\text { the closed binary operation (1'10") } \\
\text {-Enumeration of the axioms of } \\
\text { the external binary operation (3'16") }\end{array}$ & $\begin{array}{l}\text { The teacher mentions these properties } \\
\text { and solicits answers from the students. } \\
\text { The teacher writes down these properties } \\
\text { and solicits answers from the students. }\end{array}$ & Some participating. \\
\hline $\begin{array}{l}\text { Setting up of the } \\
\text { strategy ( } 4 \text { '19") } \\
\text {-the laws of the exercise are } \\
\text { closed/external ( } 32 \text { ") } \\
\text { - } \mathbb{R}^{2} \text { endowed with the } \\
\text { closed operation is an abelian } \\
\text { group (2'59") } \\
\text {-Collective strategy for the } \\
\text { rest of the exercise }\left(55^{\prime \prime}\right)\end{array}$ & $\begin{array}{l}\text { The teacher explains to the students that } \\
\text { the two operations of the exercise are } \\
\text { respectively closed and external. } \\
\text { He recalls the classical vector space } \\
\text { of } \mathbb{R}^{2} \text { and mentions that the closed } \\
\text { binary operation of the exercise is } \\
\text { the classical one. } \\
\text { The teacher indicates a strategy for the } \\
\text { case of the external binary operation. }\end{array}$ & $\begin{array}{l}\text { Recopying, some } \\
\text { participating. }\end{array}$ \\
\hline Individual research (3'09") & Silence. & Researching. \\
\hline $\begin{array}{l}\text { Beginning of the correction } \\
\text { and recap on the strategy }\left(4^{\prime} 51^{\prime \prime}\right) \\
\text {-one axiom of the external } \\
\text { binary operation holds }\left(3^{\prime} 51^{\prime \prime}\right) \\
\text {-recap on the strategy }\left(1^{\prime}\right)\end{array}$ & $\begin{array}{l}\text { The teacher proves that } \forall \alpha, \beta \in K \\
\forall x \in \mathbb{R}^{2},(\alpha+\beta) \cdot x=\alpha \cdot x+\beta \cdot x \\
\text { He recalls the research strategy for the other } \\
\text { axioms of the external binary operation. }\end{array}$ & $\begin{array}{l}\text { Recopying, some } \\
\text { participating. } \\
\text { Listening. }\end{array}$ \\
\hline Individual research (3'34") & Silence. & Researching. \\
\hline $\begin{array}{l}\text { Correction (3'47") } \\
\text {-the last axiom does not hold } \\
\text {-epilogue }\left(38^{\prime \prime}\right)\end{array}$ & $\begin{array}{l}\text { The teacher shows that the operation } \\
\text { does not satisfy the last axiom. } \\
\text { The teacher mentions that the other axioms } \\
\text { are satisfied by the external binary operation. }\end{array}$ & $\begin{array}{l}\text { Recopying, some } \\
\text { participating. } \\
\text { Listening. }\end{array}$ \\
\hline
\end{tabular}

Figure 1. Sequence of events of exercise 1 , sheet 2

are activities linked to simple and isolated tasks and correspond to (some of) the expected activities determined during the first act.

We now come to the fourth act. The teaching intervention has been separated into seven phases. The first two phases are clearly prologue phases, and we consider the third one as part of the prologue as the teacher modifies students' tasks before the period of individual research by presenting a strategy for the statement and giving a correction of part of it. The fourth and sixth phases are individual research phases, whereas the fifth and seventh ones are correction phases. The global management indicator of this exercise is $(47,22,30,0)$.

4.2.2. Exercise $5(1)(2)$, sheet 2. We first describe the a priori analysis for this statement. For point (1), the students can see that the set is included in $\mathbb{R}^{2}$ (SIT) and use the fact that $\mathbb{R}^{2}$ endowed with its usual operations is a vector space $((\mathrm{A} 1)$ or $(\mathrm{SIT}))$ in order to show that the given set is a vector subspace of $\mathbb{R}^{2}$ (A1) (by showing that the set is non empty and stable with respect to the two operations, $(\mathrm{A} 4)$ and $(\mathrm{A} 1) \times 3)$. Note that there is another choice (A6): they can show that the considered set is the vector subspace of 
$\mathbb{R}^{2}$ spanned by the vector $(5,1)$, as this notion was introduced and studied during the first lecture.

For point (2), the students can show that the set is not a vector subspace of $\mathbb{R}^{2}$ endowed with its usual operations in several ways (A6):

- show directly that the zero element of $\mathbb{R}^{2}$ is not in the given set (SIT).

- show that the set is not stable with respect to the addition by giving a counterexample (e.g. $(3,4),(8,-1)$ are in the set, but their sum is not (A1)); note that there is no real choice here, as any pair of elements gives a counterexample: this allows for a formal proof which would be unlikely at this stage of the year.

- show that the set is not closed under the external binary operation by giving a counterexample (e.g. $(3,4)$ is in the set but $2 .(3,4)=(6,8)$ is not (A1)). Again, for any element $x$ in the set and any scalar $\lambda \neq 1$, we have that $\lambda . x$ is not in the set.

The report of the second act of analysis can be found in Figure 2. As in the previous exercise, students' possible activities coincide with the expected activities. The global management indicator associated to this exercise is $(2,49,18,28)$.

\begin{tabular}{|c|c|c|}
\hline Nature of the work & Collective interventions of the teacher & Types of tasks \\
\hline $\begin{array}{l}\text { Devolution and reduction } \\
\text { of the task } \\
\left(1^{\prime} 03^{\prime}\right)\end{array}$ & $\begin{array}{l}\text { The teacher writes the wording and } \\
\text { identifies the sets as subsets of } \mathbb{R}^{2} \text {. }\end{array}$ & $\begin{array}{l}\text { Recopying. One } \\
\text { student recalls that } \\
\mathbb{R}^{2} \text { is a vector space. }\end{array}$ \\
\hline Individual research (20’30") & Silence. & Researching. \\
\hline $\begin{array}{l}\text { Correction of (1): } \\
E_{1} \text { is not empty }\left(44^{\prime \prime}\right)\end{array}$ & $\begin{array}{l}\text { He decomposes the tasks into subtasks } \\
\text { and proves that } E_{1} \text { is not empty. }\end{array}$ & Recopying. \\
\hline $\begin{array}{l}\text { Correction of (1): } \\
E_{1} \text { is closed under addition }\left(2{ }^{\prime} 53^{\prime \prime}\right)\end{array}$ & $\begin{array}{l}\text { The teacher gives the corresponding } \\
\text { correction. }\end{array}$ & Recopying. \\
\hline $\begin{array}{l}\text { Correction of (1), conclusion: } \\
E_{1} \text { is closed under . (1'57') }\end{array}$ & $\begin{array}{l}\text { The teacher gives the corresponding } \\
\text { correction. }\end{array}$ & Recopying. \\
\hline $\begin{array}{l}\text { A posteriori reflection regarding } \\
\text { the use of the graphical } \\
\text { frame }\left(6^{\prime} 20^{\prime \prime}\right)\end{array}$ & $\begin{array}{l}\text { The teacher plots the affine line which } \\
\text { corresponds to } E_{1} \text {, highlights its } \\
\text { direction and asks questions. }\end{array}$ & $\begin{array}{l}\text { Some giving vectors } \\
\text { of } E_{1} \text { that are represented } \\
\text { by the teacher. }\end{array}$ \\
\hline $\begin{array}{l}\text { Questioning the } \\
\text { students about } E_{2}(23 ")\end{array}$ & $\begin{array}{l}\text { The teacher asks the students if } E_{2} \\
\text { is a vector subspace of } \mathbb{R}^{2} \text {. }\end{array}$ & $\begin{array}{l}\text { Some saying that } 0 \notin E_{2} \\
\text { or is not stable wrt }+ \text { or }\end{array}$ \\
\hline $\begin{array}{l}\text { Collective discussion about the } \\
\text { fact that } E_{2} \text { is not empty and } \\
\text { about the way of proving it }\left(2{ }^{\prime} 25^{\prime \prime}\right)\end{array}$ & $\begin{array}{l}\text { The teachers discusses the meaning } \\
\text { of the word "empty". He highlights } \\
\text { the economy of showing that } 0 \in E_{2} \text {. }\end{array}$ & Some participating. \\
\hline $\begin{array}{l}\text { Setting up of the framework } \\
\text { to prove the non-stability } \\
\text { of } E_{2} \text { with respect to + }\left(4^{\prime} 06^{\prime \prime}\right)\end{array}$ & $\begin{array}{l}\text { The teacher encourages the students to } \\
\text { represent the affine line corresponding } \\
\text { to } E_{2} .\end{array}$ & $\begin{array}{l}\text { Listening. Some } \\
\text { reacting and answering. }\end{array}$ \\
\hline $\begin{array}{l}\text { Correction of the non-stability } \\
\text { of } E_{2} \text { with respect to }+\left(2 ' 10^{\prime \prime}\right)\end{array}$ & $\begin{array}{l}\text { The teacher gives a geometric } \\
\text { interpretation of this proposition. }\end{array}$ & Listening. \\
\hline
\end{tabular}

FiguRE 2. Sequence of events of exercice 5(1) and (2), sheet 2

4.3. Survey of some results. Within the limits of this paper, we present only the most significant results of this study. First of all, our analyses show that for most statements, students' possible activities correspond to their expected activities, as in the examples above. In the sequel, we use the notation $E_{n} S_{m}(p)$ to refer to Exercise $n$ of Sheet $m$, question $(p)$. 
4.3.1. Global results. Before coming to the global results, we give a few complements about Gilles' teaching. We first note that Gilles always allows time for a phase of individual research, whatever the exercise. Usually, each type of phase appeared at most once per exercise; in some cases though, there were two phases of individual research or of correction (e.g. see $E_{1} S_{2}$ above): in this situation, we have added the respective durations to determine the global management indicator. Note also that:

- $E_{10} S_{2}$ was not taken into account as the video does not show if there was a phase of individual research or not.

- some teaching interventions do not entirely appear on the videos which are cut before the end (mainly because the video-recording was made by Gilles himself): this is the case for $E_{5} S_{2}(3)(4), E_{5} S_{2}(5)$, $E_{6} S_{2}$ and $E_{1} S_{3}(1)$. Nevertheless, we have made the choice to include them in our results, either because we could see that the cut was near the end of the exercise (in which case we think that the global management indicator is a good approximation of what happened) or because the cut was taken into account in our indicator.

- $E_{8} S_{2}$ and $E_{8} S_{3}$ were treated during two consecutive tutorial sessions.

- for the exercises composed of several questions (e.g. $E_{5} S_{2}$ ), the cutting-out of Gilles into several different sessions has been taken into account to delimit the different statements and the corresponding teaching interventions.

We refer to Appendix B, Figure 4 for the table giving the proportion of each type of phase in each statement. The next step in our methodology is to classify the statements according to the similarities in their respective global management indicators, if possible. By observing the table, one can make the following objective remarks ${ }^{1}$ :

- some statements do not have any postlogue phase: among those, some have a prologue whose proportion is approximately 50 per cent of the total time (e. g. $E_{1} S_{2}$ ) or between 15 and 30 per cent of the total time (e. g. $E_{4} S_{2}$ ) and some do not have any prologue either (e. g. $\left.E_{9} S_{2}\right)$;

- some statements have a postlogue phase: among those, some have an individual research whose proportion is approximately 50 per cent of the total time (e. g. $\left.E_{5} S_{2}(1)(2)\right)$ or 25 per cent of the total time (e. g. $\left.E_{5} S_{2}(5)\right)$.

These first observations can be completed to classify the statements into five types, considering the distribution of the global management indicator: for type 1 the global management indicator is approximately $(50,20,30,0)$, for type 2 it is $(30,40,20,10)$, for type 3 it is $(0,45,30,20)$, for type 4 $(0,80,15,0)$ and for type 5 it is $(0,25,50,20)$. Figure 3 allows the reader to form an objective idea about this classification: of course, there are some approximations but we think that the global management indicators of the statements belonging to a given type are sufficiently similar to justify it.

\footnotetext{
${ }^{1}$ When we say that a statement does not have a particular type of phase, it could mean that this phase is, in proportion, very short or insignificant with respect to the other proportions. This will be justified and explained in the next Subsection.
} 


\begin{tabular}{|l|l|}
\hline Types and exercises & Indicator \\
\hline Type 1 & \\
$E_{1} S_{2}$ & $(47,22,30,0)$ \\
$E_{2} S_{2}$ & $(50,30,18,0)$ \\
New exercise & $(44,19,30,6)$ \\
\hline Type 2 & \\
$E_{4} S_{2}$ & $(30,42,23,0)$ \\
$E_{6} S_{2}$ & $(31,31,26,10)$ \\
$E_{11} S_{2}$ & $(13,51,35,0)$ \\
$E_{1} S_{3}(1)$ & $(23,33,32,10)$ \\
$E_{8} S_{3}$ & $(18,43,22,16)$ \\
\hline Type 3 & \\
$E_{5} S_{2}(1)(2)$ & $(2,49,18,28)$ \\
$E_{7} S_{2}$ & $(2,42,36,18)$ \\
$E_{8} S_{2}$ & $(4,47,33,13)$ \\
$E_{1} S_{3}(2)$ & $(0,54,25,20)$ \\
$E_{5} S_{3}$ & $(0,54,17,28)$ \\
\hline Type 4 & \\
$E_{5} S_{2}(3)(4)$ & $(9,76,14,0)$ \\
$E_{9} S_{2}$ & $(0,77,6,16)$ \\
$E_{12} S_{2}$ & $(0,87,12,0)$ \\
\hline Type 5 & \\
$E_{5} S_{2}(5)$ & $(0,24,55,20)$ \\
$E_{1} S_{3}(3)(4)$ & $(0,29,49,22)$ \\
\hline
\end{tabular}

FiguRE 3. Global management indicators of the exercises

4.3.2. Back to the mathematical tasks. The classification of the statements into five types according to the distribution of the global management indicators is quantitative: we now try to give a qualitative interpretation of these types in terms of the mathematical tasks that are involved. For this, we use the analyses of the first three acts.

Type 1 . The three statements of this type deal with FUG concepts that are seen for the first time during tutorial sessions (the notion of vector space in $E_{1} S_{2}$, of vector subspace in $E_{2} S_{2}$, of vector subspace spanned by a subset in the new exercise). Consequently, Gilles chooses to begin with a long prologue (about 50 per cent of the total duration), the individual research is rather short and there is no postlogue (or it is very short and not about mathematical considerations). In the prologues, Gilles recalls material about the considered FUG concepts, proposes strategies and offers direct help to the students: in particular, as for $E_{1} S_{2}$ (see Subsection 4.2), he takes charge of adaptations of type (A1) and/or (A4) during these prologues:

- for $E_{2} S_{2}$, Gilles recalls the notion of vector subspace (A1), indicates the way it can be used to show that a subset of a vector space is a vector space and introduces steps in the reasoning process (A4);

- for the new exercise, Gilles recalls the notion of vector subspace spanned by a subset (A1) and the notion of sum of two vector subspaces (A1) then proves that $\operatorname{Vect}\left(F \cup F_{a}\right)=F+F_{a}$. 
Type 2. For these statements, the teacher begins with a prologue of lesser proportion than in the first type, because the novelty factor is less significant for the students even if these exercises still deal with FUG concepts:

- in $E_{4} S_{2}$ the underlying vector space is new but the result used has already been seen in $E_{2} S_{2}$;

- in $E_{6} S_{2}$ the underlying vector space and the notion of sum of vector spaces have already been seen before but the notion of direct sum is new;

- in $E_{11} S_{2}$ the notion of Cartesian equation of a vector space is new;

- in $E_{1} S_{3}(1)$ the notion of linearly independent vectors is new but the notion of vector subspace spanned by a subset is not;

- in $E_{8} S_{3}$, the notion of basis is new but the notions of linearly dependent vectors or of Cartesian equation are not.

For this reason, the adaptations of type (A1) are easier than in the first type but are still taken in charge by Gilles; he also takes responsibility of adaptations of type (A2) or (A3). The proportion of individual research increases in comparison with type 1 and there is sometimes a postlogue in which the teacher gives an illustration, introduces new notions or additional questions:

- in $E_{6} S_{2}$ he comes back to the example of the exponential function which was mentioned in the prologue to give a possible intuition to the students;

- in $E_{3} S_{3}(1)$ he introduces the dimension of a vector space and discusses about the cardinality of different families of vectors;

- in $E_{8} S_{3}$ the question of the verification of the exactness of the Cartesian equation is evoked and a new question is given to the students: determine the coordinates of a vector in the given basis of $F$.

Type 3. In this type, there is no prologue (or it is very short and not significant), the phase of individual research is long and the proportion of the correction is more or less similar to that in type 2. In these exercises, it turns out that if there is still a degree of novelty it is minor:

- in $E_{5} S_{2}(1)(2)$, the result to use has already been seen but point (2) is more difficult as the students have to prove that the considered set is not a vector subspace;

- in $E_{7} S_{2}$, the notion of direct sum is not new but has only been seen for the case of two vector spaces;

- in $E_{1} S_{3}(2)$, the notion of linearly independent vectors is not new but the task is more delicate as the considered family is composed of three vectors (the students thus cannot use an argument of noncollinearity);

- in $E_{5} S_{3}$, the notions of basis and of dimension are not new.

The postlogue is usually more essential than in type 2 and deals with questions which will be of greater significance in the sequel of the course:

- in $E_{5} S_{2}(1)(2)$, Gilles gives a graphical representation of the sets in order to give a "visual intuition" to the students; 
- in $E_{7} S_{2}$ and $E_{8} S_{2}$, an explicit decomposition of a given vector of $\mathbb{R}^{2}$ along the direct sum is searched by means of a graphical representation;

- in $E_{1} S_{3}(2)$, Gilles mentions that the considered family of vectors is a basis of $\mathbb{R}^{3}$ as it is a maximal family composed of linearly independent vectors;

- in $E_{5} S_{3}$, the notion of rank is introduced and used to give an alternative solution to the exercise.

In terms of adaptations, students have choices to solve the statements (A6): these choices are highlighted by Gilles during the postlogue.

Type 4. In this type, there is no prologue, the individual research is very long (more than 75 per cent of the total time) and the correction is quick. The exercises bring into play simple and isolated tasks (SIT) on which the students work independently from the beginning:

- in $E_{5} S_{2}(3)(4)$, the vector space structure of $\mathcal{P}$ has already been used in $E_{4} S_{2}$ and besides Gilles recalls it at the very beginning;

- in $E_{9} S_{2}$, the notion of linear combination has already been used ( $E_{6} S_{2}$ and $\left.E_{8} S_{2}\right)$;

- in $E_{12} S_{2}$, the notion of subspace generated by a subset has been used many times before $\left(E_{7} S_{2}, E_{8} S_{2}\right.$ and $\left.E_{11} S_{2}\right)$.

Type 5. In this type, individual research occurs from the beginning (but not for a very long time) and the teacher gives a long correction (more than 50 per cent of the total time) with a postlogue which emphasizes its consequences. The students have to apply their knowledge in situations where a parameter is new:

- in $E_{5} S_{2}(5)$, the result to use is not new but the presence of the connector "or" complicates the tasks. In the postlogue, a discussion about the meaning of the locutions "or" and "and" is organised and the question whether an union/intersection of vector spaces is a vector space is solved.

- in $E_{1} S_{3}(4)$, the family of vectors under study depends from a parameter about which the students have to discuss in order to answer to the question. In the postlogue, the teacher insists on the fact that the considered family of vectors is linearly dependent and has cardinal 3 which implies that it cannot span $\mathbb{R}^{3}$.

The exercise $E_{5} S_{2}(6)$. The global management indicator is $(3,57,35,0)$ hence its distribution is not close to those of the five types determined above. More, the mathematical tasks involved in this statement are simple and isolated tasks (showing that a subset of a vector space is not a subspace has already been seen in $E_{5} S_{2}(3)(4)$ ), thus it does not seem relevant to create a new type. For these reasons, this exercise does not appear in the above table.

4.4. Prologues and postlogues. In view of some of the questions addressed in the introduction - in particular, the question of the link between lectures and practice sessions - we now give some complementary results about the institutionalisations (in the sense of Section 2.6) addressed by the teacher during the phases of prologue and postlogue. 
First of all, a quick analysis shows that the knowledge which is institutionalised during the prologue is usually clarified or illustrated during the subsequent postlogue. This is not always the case however, as some postlogues anticipate the subsequent prologue: in the new exercise, the notion of direct sum is introduced in view of $E_{6} S_{2}$.

Secondly, it seems that the purpose of the institutionalisation varies, depending on the type of the statement and when it occurs (prologue or postlogue): in relation to Douady's "dialectique outil-objet"(Douady, 1986), we will refer to an object institutio-nalisation if the purpose is to recall a theoretic notion and to a tool institutionalisation if the purpose is instead focused on the use of a notion in order to solve a problem. In the prologues of type 1 , the institutionalisation is of object type, as it is a part of a theoretical course which is very similar to the one that has been given during the corresponding lecture. In the statements of type 2, the institutionalisation is rather a tool institutionalisation: general methods adapted to the given statement are presented in order to facilitate the individual research (during the prologues), notions are recalled in the framework of the exercise (during the postlogues). In the postlogues of type 3 , this is also a tool institutionalisation: the teacher gives explicit proofs, recalls a notion in order to show its simplifying aspect or enables the students to use their intuition.

Finally, it seems interesting to link these results to the evolution of students' autonomy with respect to the different types of exercises. In type 1 , the novelty is maximal, and the teacher begins with a prologue in which the institutionalisation is object: this does not give any autonomy to the students. In type 2 , there is still a great deal of novelty, and the teacher emphasizes crucial technical aspects, and hence the degree of student autonomy is poor. In type 3, the degree of novelty is lesser, students' autonomy is greater and the institutionalisation is a tool institutionalisation. When the autonomy is great (types 4 and 5), there are no institutionalisations. We can thus hypothesize that types 2 and 3 are crucial from the point of view of the transfer of autonomy to the students, and that there is a potential link between the purpose and scheduling of the institutionalisation on the one hand and students' autonomy on the other hand.

\section{Discussion AND PERSPECTIVES}

5.1. Back to the results of our particular study. By means of our methodology, we have been able to produce a first classification of the statements proposed by the teacher in five types by means of an indicator that gives a global view of his organisation of the teaching interventions. After a deeper analysis of these types, it turns out that this first classification corresponds to a second classification of the exercises in terms of the mathematical tasks involved and of the order in which they are proposed ${ }^{2}$. For us, the correspondence of these two different classifications shows that the way the teacher globally organises his teaching interventions is strongly connected

\footnotetext{
${ }^{2}$ For example, a same mathematical task can belong to an exercise of type 1 or of type 2, depending on the moment it is seen by students: we have seen that $E_{2} S_{2}$ belongs to type 1 and $E_{4} S_{2}$ to type 2 but an a priori inversion between these two exercises would have certainly produced the corresponding inversion between the types.
} 
to his perception of the mathematical tasks being solicited in the statements and to their chronological order during the tutorial sessions. When the statements deal with new FUG concepts (types 1 and 2), the teacher organises a prologue in which he recalls the principal notions, results and methods from the lecture. When the students are allowed to research from the beginning, the degree of novelty in the exercise is less (type 3), absent (type 4) or a parameter in the exercise is new (type 5). When students are autonomous (types 3 and 5), the teacher organises a postlogue in which he sets the underlying knowledge in the context of the exercise.

In addition, an analysis of the institutionalisations has shown an evolution of the purpose (according to whether it is an object or tool institutionalisation) and the timing of these. In the exercises where students' autonomy is absent or weak (types 1 and 2), the biggest part of the institutionalisation appears before the phase of individual research, and it is either an object institutionalisation (type 1) or a tool institutionalisation (type 2). In the exercises where the autonomy is greater (types 3,4 and 5), either the institutionalisation occurs after the correction (type 3 ) or there are no institutionalisations at all. As a consequence, one may assume that there is a link between the timing, the purpose of the institutionalisations and students' autonomy according to the teacher.

Another result of our work is the establishment of a correspondence between students' expected activities (determined during the first act) and possible activities (determined during the third act) for most of the statements. For us, this shows a phenomenon of a priori management by the teacher: the inscription of a statement inside a certain type is decided a priori by the teacher and linked to the difficulty of the mathematical tasks, possibly implicitly. Roughly speaking, the teacher decides what is new in terms of knowledge and what is not. More, our analyses of the statements and of the corresponding teaching interventions, show that the mathematical tasks that are under the responsibility of students when they are autonomous are reduced to the maximum, depending on the statement type: in particular, the mathematical tasks that are involved in statements of type 1 are reduced to simple and isolated tasks by the teacher before any individual research while those that are involved in statements of type 4 are not reduced as they are already simple and isolated tasks. By his a priori management on the one hand and his reduction of the initial mathematical tasks on the other hand, the teacher does not give the students the opportunity to question the novelty of many statements with respect to their knowledge and to work autonomously with several types of knowledge adaptations.

5.2. Teaching linear algebra: some possibilities. In our particular study of linear algebra's tutorial sessions, the statements for which the teacher decides to begin with a prologue are those which deal with FUG concepts that are studied for the first time (types 1 and 2), that is those where the degree of novelty with respect to knowledge is maximal: in this case, we have seen that he chooses to reduce the initial mathematical tasks either by institutionalising concepts or methods or by taking in charge some knowledge adaptations. By this global organisation, we may suppose that 
the teacher prevents the students from being exposed to the main difficulties of these concepts: more, the students for which this sort of management for this type of concepts is above their ZPD could at best produce an immediate imitation of the teacher, thus not capturing the essence of these concepts. Our results show that the knowledge adaptations which are under the responsibility of students are not very diverse, hence one may assume that students' learning with respect to the underlying FUG concepts is not satisfactory.

Such results naturally raise the question of the possibilities or levers offered to a teacher who wants to introduce FUG concepts at the beginning of a linear algebra course (see also Subsection 2.6). Several alternative teaching sequences or long-term courses adapted to the teaching of the beginning of linear algebra have been developed (Harel, 1989; Dorier, 1990; Rogalski, 1994; Dorier, 1995; Dorier, 2000, part 2) in order to find a teaching that would be more satisfying and adapted to the specificities of FUG concepts. Among those, some of them share several hypotheses that come from the observation and analysis of students' difficulties involved in teaching linear algebra and from an epistemological analysis (Dorier, 1998; Dorier, 2000, part 1):

- to take into account the specificity of linear algebra's FUG concepts (see Subsections 2.4, 2.5 and 2.6);

- the teaching of linear algebra requires a certain number of prerequisites, in particular in the domains of mathematical logic and set theory;

- to use changes of frames or of points of view "as a unifying stimulator, first, and as a problem-solving tool, after." (Dorier, 2000, part 2 , chapter 3);

- use of the meta lever (Robert and Robinet, 1996), that is the "the use, in teaching, of information or knowledge about mathematics (Dorier, 2000);

There is also a choice of 'good' problem in which students are exposed to mathematical tasks and varied knowledge adaptations on their own (keeping in mind that it follows from general hypotheses that such a problem is only a partial introduction to the given FUG concept, see Subsection 2.6). In this spirit, we can mention the following problem as a first approach to the FUG concept of vector subspace generated by a subset (Robert, 2000): 'find all the three-row, three-column square tables, so that the sums of the elements of each row, each column and each diagonal are equal to 0.".

5.3. Perspectives. Within the theoretical framework used in this study, we have been able to adapt and amend a methodology in order to study teaching moments dedicated to the introduction of FUG concepts during tutorial sessions at the beginning of a linear algebra course. Because of the specificities of such concepts, we have stressed that the study of teaching interventions as they are organised by the teacher is essential and unavoidable: in this regard, our methodology defines several systematic indicators to study students' learning together with the teacher's activities in such moments. We thus believe that this methodology should be generalisable to 
other teaching moments dedicated to the introduction of FUG concepts at the beginning of university: in our opinion, this methodology offers an easy way (as a first approach) to compare different 'teaching styles', in the case where teacher's interventions during classroom events are crucial.

To illustrate the possibilities offered by this methodology, we have also implemented it in a particular case: another perspective of our work is thus to continue our investigation of introductory linear algebra tutorial sessions with other teachers, possibly in foreign universities, either to spot invariants or variabilities in teachers' practices or to highlight the spectrum of teachers' possibilities.

Our study of the lectures and tutorial sessions of our corpus has allowed us to observe several phenomena linked to issues concerning the secondarytertiary transition.

Firstly, a double institutionalisation phenomenon has already been emphasized: a classical institutionalisation during the lectures and an institutionalisation which is linked with the mathematical tasks during the tutorial sessions. It seems to us that this phenomenon should be questioned in several regards. What is the purpose of the institutionalisation given during the lectures in relation to students' learning? What kind of links are made by the students between both institutionalisation types? Is it possible to explain the role of the institutionalisation which occurs during the tutorial sessions in terms of the transfer of autonomy to the students? It would also be interesting to build a method to compare systematically both types of institutionalisations; a first step for this purpose would be to design a methodology to study the lectures: to our best knowledge, this has not been done yet.

Secondly, we have been able to spot an expertise concerning the management of the conversion between different representation registers in Gilles' practice. However, the conversion transformations are not explained or taught (Dorier, 1998) whereas they are a main source of difficulties when learning mathematics (Duval, 2006). It should be an interesting matter to investigate whether conversions contribute to students' difficulties in the secondary-tertiary transition.

Last, we have also spotted discursive regularities in Gilles' interactions with the students or in its discourse during the correction phases. Some research point out that logic is in a way absent from teacher's discourse and replaced by reasoning rules that are not taught and interwoven with mathematical knowledge (Durand-Guerrier and Arsac, 2003). In relation to this, one could ask in what extent reasoning rules appear in the teacher's discourse during the introduction of new mathematical knowledge in tertiary level, more particularly in the case of FUG concepts.

Appendix A

\section{Sheet 2: Vector spaces and subspaces}

Exercise 1

In $\mathbb{R}^{2}$, define the operations $(x, y)+\left(x^{\prime}, y^{\prime}\right)=\left(x+x^{\prime}, y+y^{\prime}\right), \quad \alpha .(x, y)=$ 
$(\alpha x, 0)$. Is $\mathbb{R}^{2}$ endowed with these operations a vector space?

Exercise 2

Show that the set of matrices $M=\left(\begin{array}{ll}a & c \\ b & d\end{array}\right)$ such that $a+d=0$ is a vector space.

\section{Exercise 4}

Let $a$ and $b$ be real numbers. Show that the set of solutions of the differential equation $y^{\prime \prime}+a y^{\prime}+b y=0$ over $[0 ; 1]$ is a vector space.

\section{Exercise 5}

Let $\mathcal{P}$ denote the set of functions of class $C^{\infty}$ from $\mathbb{R}$ to $\mathbb{R}$. Which of the following subspaces are vector spaces and which are not?

(1) $\left\{\left(x_{1}, x_{2}\right) \in \mathbb{R}^{2} \mid x_{1}=5 x_{2}\right\}$.

(2) $\left\{\left(x_{1}, x_{2}\right) \in \mathbb{R}^{2} \mid x_{1}+x_{2}=7\right\}$.

(3) $\{f \in \mathcal{P} \mid f(0)=1\}$.

(4) $\{f \in \mathcal{P} \mid f(x)=f(-x)$ for all $x \in \mathbb{R}\}$.

(5) $\left\{\left(x_{1}, x_{2}, x_{3}\right) \in \mathbb{R}^{3} \mid x_{1}+x_{2}=0\right.$ or $\left.x_{1}=x_{3}\right\}$.

(6) $\left\{\left(x_{1}, x_{2}, x_{3}\right) \in \mathbb{R}^{3} \mid x_{1}^{2}+x_{2}^{2}=x_{3}^{2}\right\}$.

\section{New exercise}

Let $F$ (resp. $F_{a}$ ) be the vector subspace of $\mathbb{R}^{2}$ spanned by the vector $(1,1)$ (resp. $(2, a)$ ), where $a$ is a real parameter. Determine the vector subspace of $\mathbb{R}^{2}$ spanned by $F \cup F_{a}$ according to $a$.

\section{Exercise 6}

Let $E$ be the set of functions from $\mathbb{R}$ to $\mathbb{R}, F$ (resp. $G$ ) be the subset of $E$ that consists of even (resp. odd) functions. Show that $F$ and $G$ are vector subspaces of $E$ and that $E=F \oplus G$.

\section{Exercise 7}

Define the following vector subspaces of $\mathbb{R}^{2}$ :

$D_{1}=\left\{(a, b) \in \mathbb{R}^{2} \mid b=0\right\} ; D_{2}=\left\{(a, b) \in \mathbb{R}^{2} \mid a=0\right\} ; D_{3}=\left\{(a, b) \in \mathbb{R}^{2} \mid a=b\right\}$.

Show that $\mathbb{R}^{2}=D_{1}+D_{2}+D_{3}$. Is it a direct sum?

Exercise 8

Let $D$ be the vector subspace of $\mathbb{R}^{3}$ spanned by the vector $(-1,1,2)$ and define the set $P=\left\{(x, y, z) \in \mathbb{R}^{3} \mid x+2 y-z=0\right\}$. Show that $P$ is a vector subspace strictly included in $\mathbb{R}^{3}$. Show that any vector $u=(x, y, z) \in \mathbb{R}^{3}$ can be uniquely decomposed as $(x, y, z)=\left(x^{\prime}, y^{\prime}, z^{\prime}\right)+\left(x^{\prime \prime}, y^{\prime \prime}, z^{\prime \prime}\right),\left(x^{\prime}, y^{\prime}, z^{\prime}\right) \in P$ and $\left(x^{\prime \prime}, y^{\prime \prime}, z^{\prime \prime}\right) \in D$.

\section{Exercise 9}

Consider the $n$-tuples $\left(x_{1}, \cdots, x_{n}\right),\left(x_{1}^{\prime}, \cdots, x_{n}^{\prime}\right)$ and let $\lambda$ be a real paramater. Express the following $n$-tuples as a liear combination of $\left(x_{1}, \cdots, x_{n}\right)$ and $\left(x_{1}^{\prime}, \cdots, x_{n}^{\prime}\right):\left(x_{1}+x_{1}^{\prime}, \cdots, x_{n}+x_{n}^{\prime}\right),\left(x_{1}-x_{1}^{\prime}, \cdots, x_{n}-x_{n}^{\prime}\right),(0, \cdots, 0)$, 
$\left(x_{1}, \cdots, x_{n}\right),\left(\lambda x_{1}, \cdots, \lambda x_{n}\right)$.

Exercice 10

Can we find two real numbers $x$ and $y$ such that the vector $v=(-2, x, y, 3)$ is a linear combination of the vectors $u_{1}=(1,-1,1,2)$ and $u_{2}=(-1,2,3,1)$ ?

\section{Exercise 11}

Give a cartesian equation of the following vector subspaces:

(1) $F=\operatorname{Vect}\{(1,3)\} \subset \mathbb{R}^{2}$.

(2) $G=\operatorname{Vect}\{(1,2,3) ;(1,0,1)\} \subset \mathbb{R}^{3}$.

(3) $H=\operatorname{Vect}\{(1,0,1,0)\} \subset \mathbb{R}^{4}$.

Exercise 12

Define

$$
E=\left\{\left(\begin{array}{ccc}
a-b & b-c & 2 c \\
2 a & a+b & -b \\
b & c & a
\end{array}\right), a, b, c \in \mathbb{R}\right\} .
$$

Show that $E$ is a vector subspace of $\mathcal{M}_{3}(\mathbb{R})$. Show that $E$ is spanned by the following matrices

$$
\left(\begin{array}{lll}
1 & 0 & 0 \\
2 & 1 & 0 \\
0 & 0 & 1
\end{array}\right), \quad\left(\begin{array}{ccc}
-1 & 1 & 0 \\
0 & 1 & -1 \\
1 & 0 & 0
\end{array}\right), \quad\left(\begin{array}{ccc}
0 & -1 & 2 \\
0 & 0 & 0 \\
0 & 1 & 0
\end{array}\right) .
$$

\section{Sheet 3 : Sets of vectors}

Exercise 1 [the only part of question (4) that has been videorecorded concerns the question of the linear dependence of the considered subset]

In the vector space $\mathbb{R}^{3}$, decide whether or not the subsets consisting of the following vectors are linearly dependent or span $\mathbb{R}^{3}$.

(1) $u_{1}=(-1,2,1), u_{2}=\left(-\frac{1}{\sqrt{2}}, \sqrt{2}, \frac{1}{\sqrt{2}}\right)$.

(2) $u_{1}=(-1,1,1), u_{2}=(1,1,-2), u_{3}=(1,2,1)$.

(3) $u_{1}=(1,2,3), u_{2}=(3,2,1), u_{3}=(1,1,1)$.

(4) $u_{1}=(1,1,1), u_{2}=(m, 1, m), u_{3}=\left(m, m, m^{2}\right)$, where $m$ is a real parameter.

\section{Exercise 8}

Let $u=(1,2,3), v=(2,-1,1), w=(2,-3,-1) \in \mathbb{R}^{3}$.

(1) Show that the subset consisting of $u, v$ and $w$ is linearly dependent and give a basis of $F=\operatorname{Vect}\{u, v, w\}$.

(2) Give a cartesian equation of $F$.

Exercise 5

Define $v_{1}=(2,1,3,1), v_{2}=(1,2,0,1), v_{3}=(-1,1,-3,0) \in \mathbb{R}^{4}$ and let $E=\operatorname{Vect}\left\{v_{1}, v_{2}, v_{3}\right\}$. Give the dimension and a basis of $E$.

\section{Appendix B}

In the following chronological table, we give the results concerning the global indicators in each statement of the corpus; we also mention the exact 
duration of each phase (for a given phase, this data appears italicized in brackets) and the total duration of the exercise. The durations are given in terms of minutes and seconds in order to minimize the rounding errors in the proportions.

\begin{tabular}{|c|c|c|c|c|c|}
\hline Exercise & Prologue & Research & Correction & Postlogue & Total \\
\hline$E_{1} S_{2}$ & 47 (14'08") & $22\left(6^{\prime} 41^{\prime \prime}\right)$ & 30 (9'06") & 0 & (29'55") \\
\hline$E_{2} S_{2}$ & 50 (13'53") & 30 (8'24") & 18 (5'08") & 0 & (27'25") \\
\hline$E_{4} S_{2}$ & 30 (12'51") & $42\left(18^{\prime} 06^{\prime \prime}\right)$ & 23 (9'59") & 0 & (42'17") \\
\hline$E_{5} S_{2}(1)(2)$ & $2(58 ")$ & 49 (20’34”) & 18 (7'48") & 28 (11'50") & (41'33") \\
\hline$E_{5} S_{2}(3)(4)$ & 9 (2'26") & 76 (20'42") & 14 (3'59") & 0 & (27'07") \\
\hline$E_{5} S_{2}(5)$ & 0 & 24 (8'04") & 55 (18'14”) & 20 (6'42") & (33') \\
\hline$E_{5} S_{2}(6)$ & $3(40 ")$ & 57 (12'17") & 35 (7'36") & 0 & (21'33") \\
\hline New exercise & 44 (32'11") & 19 (13'50") & 30 (21'40”) & 6 (4’35”) & (1h12'16") \\
\hline$E_{6} S_{2}$ & 31 (7'24") & 31 (7'33") & $26\left(6^{\prime} 16^{\prime \prime}\right)$ & 10 (2'33") & $\left(23^{\prime} 56^{\prime \prime}\right)$ \\
\hline$E_{7} S_{2}$ & $2\left(1^{\prime}\right)$ & $42\left(14{ }^{\prime} 40 "\right)$ & 36 (12'47") & $18\left(6^{\prime} 15^{\prime \prime}\right)$ & $\left(34{ }^{\prime} 42 "\right)$ \\
\hline$E_{8} S_{2}$ & 4 (4’15”) & 47 (42'55") & 33 (30'16") & 13(11'39") & (1h29'59") \\
\hline$E_{9} S_{2}$ & 0 & 77 (25'03”) & $6\left(2^{\prime} 01 "\right)$ & $16\left(5^{\prime} 16^{\prime \prime}\right)$ & (32'20") \\
\hline$E_{11} S_{2}$ & 13 (6'35") & 51 (24'58") & 35 (17'07") & 0 & $(48 ' 40 ")$ \\
\hline$E_{12} S_{2}$ & 0 & 87 (21'17") & 12 (2'58") & 0 & (24'15") \\
\hline$E_{1} S_{3}(1)$ & 23 (10'17") & 33 (14'39") & 32 (14'26") & 10 (4'40") & $\left(44^{\prime} 02 "\right)$ \\
\hline$E_{1} S_{3}(2)$ & 0 & 54 (13'48") & 25 (6'22") & $20\left(5^{\prime} 05^{\prime \prime}\right)$ & $(25 ' 25 ")$ \\
\hline$E_{1} S_{3}(3)(4)$ & 0 & 29 (12'30”) & 49 (21'09") & 22(9'28") & (43'07") \\
\hline$E_{8} S_{3}$ & 18 (12'27") & 43 (30'06") & 22 (15'17") & 16(11'20") & (1h08'35") \\
\hline$E_{5} S_{3}$ & 0 & $54\left(25^{\prime} 50^{\prime \prime}\right)$ & $17\left(8^{\prime} 18^{\prime \prime}\right)$ & 28(13'31") & $\left(47{ }^{\prime} 39 "\right)$ \\
\hline
\end{tabular}

Figure 4. Proportion of the global indicators in the exercises

\section{REFERENCES}

Bridoux, S. (2011). Enseignement des premières notions de topologie à l'université. Une étude de cas [Teaching basic concepts of topology at university level. A case study]. Thèse de Doctorat, Université Paris Diderot.

Brousseau, G. (1997). Theory of didactical situations in mathematics. Dordrecht: Kluwer Academic Publishers.

Dorier, J.-L. (1990) Contribution à l'étude de l'enseignement à l'université des premiers concepts d'algèbre linéaire. Approche historique et didactique $[A$ contribution to the study of the teaching of linear algebra's first concepts at the university. A historical and didactical approach]. Thèse de Doctorat de l'Université Joseph Fourier, Grenoble.

Dorier, J.-L. (1995). Meta level in the teaching of unifying and generalizing concepts in mathematics. Educational Studies in Mathematics, 29(2), 175-197.

Dorier, J.-L. (1998). État de l'art de la recherche en Didactique à propos de l'enseignement de l'algèbre linéaire [Latest developments in Didactics about the teaching of linear algebra]. Recherches en Didactique des Mathématiques, 18(2), 191-230.

Dorier, J.-L. (Ed.). (2000). On the Teaching of Linear Algebra. Dordrecht: Kluwer Academic Publishers.

Douady, R. (1986). Jeu de cadres et dialectique outil/objet [Interplays between different frames and tool-object dialectic]. Recherches en Didactique des Mathématiques, 7(2), 5-31.

Durand-Guerrier, V., \& Arsac, G. (2003). Méthodes de raisonnement et leurs modélisations logiques. Spécificité de l'analyse. Quelles implications didactiques ? [Reasoning methods and their logical models. Specificity of calculus. 
Which didactic implications?]. Recherches en Didactique des Mathmatiques, $23(3), 295-342$.

Duval, R. (2006). A cognitive analysis of problems of comprehension in the learning of mathematics. Educational Studies in Mathematics, 61(1-2), 103-131.

Engeström, Y., Miettinen, R., \& Punamäki, R.-L. (Eds.). (1999). Perspectives on Activity Theory. Cambridge University Press.

Harel, G. (1989). Learning and Teaching Linear Algebra: Difficulties and an Alternative Approach to Visualizing concepts an Processes. Focus on Learning Problems in Mathematics 11, 139-148.

Horoks, J., \& Robert, A. (2007). Tasks designed to highlight task-activity relationships. Journal of Mathematics Teacher Education 10, 279-287.

Leontiev, A.N. (1975). Activité, conscience, personnalité [Activity, consciousness, personality]. Moscou: Édition du progrès.

Leplat, J. (1997). Regards sur l'activité en situation de travail [About the activity in a job situation.] Paris : PUF.

Mac Lane, S. (1998). Categories for the working mathematician. Second Edition. Graduate Texts in Mathematics, 5, New-York: Springer-Verlag.

Pariès, M., Robert, A., \& Rogalski J. (2009). Comment l'enseignant de mathématiques, en classe, met ses élèves sur le chemin des connaissances : un point de vue méthodologique en didactique des mathématiques [How does the mathematics teacher guide his students towards knowledge inside the classroom: a methodological point of view in mathematics didactics]. Travail et apprentissages, 3, 95-123.

Robert, A. (1987). De quelques spécificités de l'enseignement des mathématiques dans l'enseignement post-obligatoire [Some specificities about teaching mathematics at the tertiary level]. Cahier de Didactique des Mathématiques, 47, IREM de Paris VII.

Robert, A., \& Robinet, J. (1996). Prise en compte du méta en Didactique des Mathématiques [Taking into account the "meta"in mathematics didactics]. Recherches en Didactique des Mathématiques, 16(2), 145-176.

Robert, A. (1998). Outil d'analyse des contenus mathématiques à enseigner au Lycée et l'Université [Tools for the analysis of the mathematical contents taught at high school and university]. Recherches en Didactique des Mathématiques, 18(2), 139-190.

Robert, A. (2000). Level of conceptualization and secondary school math education. In Dorier, J.-L. (Ed.), On the Teaching of Linear Algebra, Dordrecht: Kluwer Academic Publishers.

Robert, A. (2012). A didactical framework for studying students' and teachers' Activities when learning and Teaching Mathematics. International Journal for Technology in Mathematics Education, 19(4).

Robert, A., \& Hache, C. (2013). Why and how to understand what is at stake in a mathematics class. In Vandebrouck, F. (Ed.), Mathematics Classrooms: Students' Activities and Teacher's Practices (pp 23-73), Université Paris Diderot, France Sense Publisher.

Rogalski, J. (2013). Theory of Activity and developmental frameworks for an analysis of teachers' practices and students' learning. In Vandebrouck, F. (Ed.), Mathematics Classrooms: Students' Activities and Teacher's Practices (pp 322), Université Paris Diderot, France Sense Publisher.

Rogalski, M. (1994). L'enseignement de l'algèbre linéaire en première année de DEUG A [The teaching of linear algebra during the first year of university]. La Gazette des Mathématiciens, 60, 39-62.

Stein, M. K., Grover, B. \& Henningsen M. (1996). Building student capacity for 
mathematical thinking and reasoning: An analysis of mathematical tasks used in reform classrooms. American Educational Research Journal, 33(2), 455-488. Vandebrouck, F. (Ed.). (2013). Mathematics Classrooms: Students'Activities and Teacher's Practices. Université Paris Diderot, France, Sense Publishers. 